\section{KẾT LUÂN}

Trong 69 bệnh nhân u máu gan, có $85,5 \%$ vào viện do đau bụng, trên siêu âm có $78,58 \%$ có hình ảnh tăng âm sau u, trên phim chụp cắt lớp vi tính trước tiêm thuốc cản quang chủ yếu là hình ảnh giảm tỷ trọng đồng nhất $(96,9 \%)$, không có trường hợp nào tăng tỷ trọng trước tiêm.

Sau điều trị, hầu hết các bệnh nhân đều cải thiện triệu chứng $(94,2 \%)$, trong đó có $82,6 \%$ hết triệu chứng và $11,6 \%$ có cải thiện. Có $91 \%$ có kêt quả sau mổ tốt gồm các trường hợp không có biến chứng hoặc biến chứng độ I chỉ cần chăm sóc, điều trị nôi khoa sau mổ.

Lời cảm ơn. Chúng tôi xin gửi lời cảm ơn tới Bệnh viện Hữu nghị Việt Đức đã tạo điều kiện cho chúng tôi trong quá trình thực hiện nghiển cứu này.

\section{TÀI LIỆU THAM KHẢO}

1. Bajenaru N, Balaban V, Savulescu F, et al. Hepatic hemangioma -review. J Med Life. 2015;8 Spec Issue:4-11.

2. Erdogan $D$, Busch OR, van Delden OM, et al. Management of liver hemangiomas according to size and symptoms. J Gastroenterol Hepatol. Nov
2007;22(11):1953-8. 1746.2006.04794.x

doi:10.1111/j.1440-

3. Evans J, Willyard CE, Sabih DE. Cavernous Hepatic Hemangiomas. StatPearls. 2021.

4. Farges O, Daradkeh S, Bismuth H. Cavernous hemangiomas of the liver: are there any indications for resection? World J Surg. Jan-Feb 1995;19(1):19-24. doi:10.1007/BF00316974

5. Abdel Wahab M, El Nakeeb A, Ali MA, et al. Surgical Management of Giant Hepatic Hemangioma: Single Center's Experience with 144 Patients. J Gastrointest Surg. May 2018;22(5):849858. doi:10.1007/s11605-018-3696-y

6. Starzl T.E, et al. Excisional treatment of cavrernous hemangioma of the liver. Ann Surg Oncol. 1980;192(1):25-27.

7. Đoàn Ngoc Giao. Nghiên cứu chẩn đoán, chỉ định phâ̂u thuật và kết quả điều trị u máu gan ở người lớn. Học Viện Quân Y; 2009.

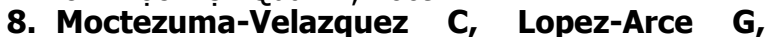
Martinez-Rodriguez LA, et al. Giant hepatic hemangioma versus conventional hepatic hemangioma: clinical findings, risk factors, and management. Rev Gastroenterol Mex. Oct-Dec 2014;79(4):229-37.

doi:10.1016/j.rgmx.2014.08.007

9. Lerner S.M. et al. Giant cavernous liver hemangiomas: effect of operative approach on outcome. Arch Surg. 2004;139(818-823)

\title{
ĐÁNH GIÁ THỰC TRẠG TUÂN THỦ ĐIỀU TRI Ở BỆNH NHÂN BỆNH PHỔI TẮC NGHẼN MAN TÍNH ĐIỀU TRI NGOẠI TRÚ
}

\section{TÓM TẮT}

Mục tiêu: Mô tả thực trạng tuân thủ điều trị ở bênh nhân Bênh phổi tẳc nghẽ̃n man tính (COPD). Đối tượng và phương pháp: Nghiên cứu mô tả cắt ngang được thực hiện trên bệnh nhân COPD điều trị ngoại trú tại khoa khám bệnh, bệnh viện Lão khoa Trung ương và bệnh viện đa khoa Đống Đ̇a. Tuân thủ sử dụng thuốc của bệnh nhân được đánh giá theo thang Morisky-8. Bộ câu hỏi gồm 8 câu liên quan đến việc sử dụng thuốc. Đánh giá tuân thủ sử dụng thuốc dựa vào tổng điểm: 8 điểm là tuân thủ tốt, 6 đến 7 điểm là tuân thủ trung bình, dưới 6 điểm là tuân thủ kém. Kết quả: Nghiên cứu của chúng tôi được thực hiện trên 286 người bệnh điều trị COPD ngoại trú. Độ tuổi trung bình 69,3 $\pm 9,2$ tuổi. Tyy lệ bệnh nhân tuân thủ điêu trị tốt 49,3\%, bệnh nhân tuân thủ trung bình là $32,2 \%$, bệnh nhân tuân thủ kém là $18,5 \%$. Có 25,5\% bệnh nhân thỉnh thoảng quên sử dụng thuốc,

\footnotetext{
${ }^{1}$ Bệnh viện Lão khoa Trung ương, ${ }^{2}$ Bộ môn Lão khoa - Trường Đai hoc Y Hà Nội Chịu trách nhiệm chính: Tạ Hữu Ánh Email: huuanhbs@yahoo.com.vn Ngày nhận bài: 12.8 .2021

Ngày phản biên khoa họ: 11.10.2021

Ngày duyệt bài: 22.10 .2021
}

23,5\% trong 2 tuân có ngày không dùng thuốc $17,8 \%$ cảm thấy khó khăn khi phải nhớ dùng tất cả các loại thuốc. Kết luận: Tỷ lệ bệnh nhân chưa tuân thủ điều trị tốt (tuân thủ trung bình và kém) trong nghiên cứu của chúng tôi khá cao $50,7 \%$, mà nguyên nhân chính là do bệnh nhân quên dùng thuốc hoặc khó khăn khi nhớ tất cả các loại thuốc phải dùng. Để khắc phục tình trạng này cần có sự hố trợ nhắc nhở thường xuyên của người nhà, của nhân viên y tế để giúp bệnh nhân tuân thủ điều trị tốt hơn.

Từ khóa: COPD, bệnh nhần ngoại trú, tuân thủ dùng thuốc

SUMMARY
ASSESSMENT THE MEDICATION ADHERENCE
IN OUTPATIENTS WITH CHRONIC
OBSTRUCTIVE PULMONARY DISEASE
Objective: To investigate the situation of
medication adherence in outpatients with chronic
obstructive pulmonary disease (COPD). Methods: A
cross-sectional study was conducted in outpatients
with COPD in Outpatient department in National
Geriatric Hospital and Dong Da General Hospital.
Medication adherence was defined by using Morisky-8
scale. The scale has 8 questions. There are three
levels of adherence based on total score: 8 scores:
high, 6 -7 scores: medium, < 6 scores: low. Results:


A total of 286 outpatients with COPD was recruited in the study. Mean age was $69.3 \pm 9.2$ years old. The proportions of high, medium and low adherence were $49.3 \%, 32.2 \%$ and $18.5 \%$, respectively. Patients who sometimes forgot to take pills were accounted for $25.5 \%$, who did not take medications in the past two weeks was $23.5 \%$. $17.8 \%$ had difficulty remembering to take all medications. Conclusion: The prevalence of non -adherence of outpatients with COPD was $50.7 \%$. The main causes were to forget to take pills and to have difficulty remembering take medications. To overcome this situation, it is necessary to have regular support and reminder family members and medical staff.

Keywords: COPD, outpatients, medication adherence

\section{I. ĐẶT VẤN ĐỀ}

Bệnh phổi tắc nghẽn mạn tính (COPD) là bệnh lý hô hấp mạn tính có đặc trưng bởi sự tắc nghẽn luồng khí thở ra không hồi phục hoàn toàn, sự cản trở thông khí này thường tiến triển từ từ và liên quan đến phản ứng viêm bất thường của phổi với các phân tử hoặc khí độc hại, trong đó khói thuốc lá đóng vai trò hàng đẩu. Bệnh phổi tắc nghẽn mạn tính có thể dự phòng và điều trị được [1], [8]. Theo Tổ chức $Y$ tế Thế giới (WHO), năm 1997 trên toàn thế giới đã có khoảng 600 triệu người mắc Bệnh phổi tắc nghẽn mạn tính, bệnh được xếp hàng thứ tư trong các nguyên nhân gây tử vong và là nguyên nhân gây tàn phế đứng hàng thứ mười hai. Dự báo đến năm 2030 COPD sẽ đứng hàng thứ ba trong các nguyên nhân gây tử vong sau bệnh tim mạch, bệnh ung bướu và đứng hàng thứ năm trong gánh nặng bệnh tật toàn cầu, làm gia tăng đáng kể gánh nă̆ng về kinh tế và xã hội [8]. Ở Việt Nam, theo điêu tra của Đinh Ngọc Sỹ (2011), tỷ lệ mắc bệnh COPD ở các đối tượng trên 40 tuổi có tỷ lệ 4,2\% [3].

Việt Nam đã chính thức bước vào giai đoạn già hóa dân số năm 2011, với tỷ lệ người cao tuổi trên 60 tuổi chiếm $10 \%$. Dự báo đến năm 2030 sẽ có gần 19 triệu và năm 2050 là hơn 28 triệu người cao tuổi. Hà Nội là một trong những Thành phố có tỷ lệ người cao tuổi lớn nhất cả nước [2].

Hiê̂n nay, các nghiên cứu tại Việt Nam và trên thế giới sử dụng nhiều khái niệm khác nhau để mô tả việc sử dụng thuốc của bệnh nhân như: tuân thủ, sử dụng thuốc phù hợp, tuân thủ điều trị, hay tuân thủ sử dụng thuốc, tuân thủ dùng thuốc. Có nhiều phương pháp có thể sử dụng để đánh giá sự tuân thủ điêu trị ở bệnh nhân COPD. Trong đó, đánh giá tuân thủ dùng thuốc thông qua bộ câu hỏi Morisky là phương pháp đánh giá có tính ứng dụng cao trên lâm sàng do dễ thực hiện, tiết kiệm thời gian và chi phí [6]. Bộ cấu hỏi Morisky đã được đánh giá có giá trị cao khi áp dụng tại Việt Nam [7]. Chúng tôi tiến hành đề tài này với mục tiêu: Mô tả thực trạng tuân thủ điều trị ở bệnh nhân Bệnh phổi tắc nghẽn mạn tính và một số yếu tố liên quan.

\section{II. ĐỐI TƯợNG VÀ PHƯƠNG PHÁP NGHIÊN CỨU}

\section{1. Đối tượng nghiên cứu}

*Đối tượng nghiên cứu: là các bệnh nhân được chẩn đoán COPD đến khám và điều trị tại Bệnh viện Lão khoa trung ương và Bệnh viện đa khoa Đống Đa.

*Tiêu chuẩn chọn bệnh nhân:

- Bệnh nhân được chẩn đoán COPD theo GOLD 2018 [8].

+ FEV1/FVC $<70 \%$ sau test hồi phục phế quản.

+ FEV1 giảm.

- Đồng ý tham gia nghiên cứu

*Tiêu chuẩn loại trừ:

- Bệnh nhân có dấu hiệu thần kinh khu trú.

- Bểnh nhân có dấu hiệu rối loạn tâm thần.

- Có các bệnh lý cấp tính (bệnh lý tim mạch cấp, đột quỵ cấp, suy hô hấp cấp...).

2.2. Địa điểm và thời gian nghiên cứu:

- Địa điểm nghiên cứu. Bệnh viện Lão khoa trung ương, số $1 \mathrm{~A}$ - Phương Mai - Đống Đa - Hà Nội và Bệnh viện đa khoa Đống Đa - Hà Nội.

- Thời gian nghiên cứu. Từ tháng 09/2020 đến tháng 09/2021.

\subsection{Phương pháp nghiên cứu}

- Thiết kế nghiên cứu. Nghiên cứu mô tả cắt ngang

- Công cụ thu thập số liệu:

- Bệnh án nghiên cứu

- Hồ sơ bệnh án ngoại trú.

* Các biến số nghiên cứu và cách đánh giá

- Đắc điểm chung: Tuổi, giới tính.

- Yểu tố nguy cơ: thuốc lá, nghề nghiệp tiếp xúc khói bụi, tiên sử bản thân.

- Bệnh lý: Thời gian điều trị bệnh COPD, bệnh lý mắc kèm được hỏi theo danh sách có sẵn.

- Thuốc điêu trị COPD, Số nhóm thuốc điều trị đang được sử dụng cho người bệnh (khai thác dựa vào Hồ sơ quản lý bệnh ngoại trú)

- Tuân thủ sử dụng thuốc:

Tuân thủ sử dụng thuốc của bệnh nhân được đánh giá theo thang Morisky-8. Bộ câu hỏi gồm 8 câu liên quan đến việc sử dụng thuốc được thiết kế để làm giảm sai số trả lời "Có" của bênh nhân. Đối với câu hỏi $1-4$ và $6-8$ mối câu trả lời "Không" được tính 1 điểm. Riêng câu số 5 , trả lời "Có" tính 1 điểm. Điểm tuân thủ của bệnh nhân là tổng điểm 8 câu hỏi.

Đánh giá tuân thủ sử dụng thuốc: [9]. 
+ Tổng điểm 8 : Tuân thủ tốt

+ Tổng điểm $6-7$ : Tuân thủ trung bình

+ Tổng điểm $<6$ : Tuân thủ kém

- Phân loại mức độ tắc nghẽn đường thở [1] [8].

Giai đoan: $\quad+\mathrm{FEV}_{1} / \mathrm{FVC}<70 \%$. Giá trị FEV1 sau test hồi phục phế quản

I : Nhe $\quad+\mathrm{FEV}_{1} \geq 80 \%$ trị số lý thuyết.

II: Trung bình $+50 \% \leq \mathrm{FEV} 1<80 \%$ trị số lý thuyết.

III: Nặng $+30 \% \leq \mathrm{FEV}_{1}<50 \%$ trị số lý thuyết

IV: Rất nặng $\quad+\mathrm{FEV}_{1}<30 \%$ trị số lý thuyết

\subsection{Xử lý số liệu}

- Nhập liệu bằng phần mềm Redcap, Trường Đại học Y Hà Nội, (http://redcap.hmu.edu.vn/)

- Xử lý số liệu trên phần mềm SPSS 20.0.

\section{KẾT QUẢ NGHIÊN CỨU}

3.1. Đặc điểm chung nhóm nghiên cứu. Nghiên cứu được thực hiện trên 286 người bệnh điêu trị COPD ngoại trú. Bệnh nhân cao tuổi nhất là 91 tuổi, bệnh nhân ít tuổi nhất là 33 tuổi.

Độ tuổi trung bình 69,3 \pm 9,2.

Bảng 1. Đặc điểm chung nhóm nghiên cứu

\begin{tabular}{|c|c|c|c|c|}
\hline \multirow{2}{*}{\multicolumn{2}{|c|}{ Đặc điểm }} & \multicolumn{2}{|c|}{ Rối loạn tắc nghẽn CNHH } & \multirow{3}{*}{$\begin{array}{c}\text { Tổng } \\
169\end{array}$} \\
\hline & & Giai đoạn nhẹ & Giai đoạn (TB- Rất nặng) & \\
\hline \multirow[b]{2}{*}{ Nam } & $\mathrm{n}$ & 29 & 140 & \\
\hline & Tỷ lệ (\%) & $33.3 \%$ & $70.4 \%$ & $59.1 \%$ \\
\hline \multirow[b]{2}{*}{ Nữ } & $\mathrm{n}$ & 58 & 59 & 117 \\
\hline & Tỷ lệ (\%) & $66.7 \%$ & $29.6 \%$ & $40.9 \%$ \\
\hline \multirow{2}{*}{ Tuổi } & $n$ & 87 & 199 & 286 \\
\hline & Trung bình & $68,9 \pm 10,5$ & $69,4 \pm 8,7$ & $69,3 \pm 9,2$ \\
\hline \multirow{2}{*}{ Tổng } & $\mathrm{n}$ & $87(30,4 \%)$ & $199(69,6 \%)$ & $286(100 \%)$ \\
\hline & Tỷ lệ (\%) & $100.0 \%$ & $100.0 \%$ & $100.0 \%$ \\
\hline
\end{tabular}

Nhận xét: Bệnh nhân trong nhóm nghiên cứu chủ yếu là người cao tuối, với độ tuối trung bình $69,29 \%$. Nam giới có tỷ lệ cao hơn rõ rệt $59,1 \%$ so với nữ giới là $40,9 \%$. Điều này phù hợp với bệnh phổi tắc nghẽn mạn tính thường xảy ra ở người cao tuổi, chủ yếu ở nam giới.

Rối loạn tắc nghẽn chức năng hô hấp giai đoạn nhẹ (giai đoạn 1) có 87 bệnh nhân chiếm tỷ lệ 30,4\%. Rối loạn tắc nghẽn chức năng hô hấp giai đoạn trung bình đến rất nặng có 199 bệnh nhân, chiếm tỷ lệ 69,6\%.

\section{2. Ảnh hưởng của yếu tố nguy cơ trong nhóm nghiên cứu}

Bảng 2. Đánh giá yếu tố nguy cơ

\begin{tabular}{|c|c|c|c|c|c|}
\hline \multirow{2}{*}{\multicolumn{3}{|c|}{ Yếu tố nguy cơ }} & \multicolumn{2}{|c|}{ Chức năng hô hấp } & \multirow{3}{*}{$\begin{array}{c}\text { Tổng } \\
161\end{array}$} \\
\hline & & & Giảm nhẹ (giai đoạn 1) & Giảm TB- rất nặng & \\
\hline \multirow{6}{*}{$\begin{array}{l}\text { Hút } \\
\text { thuốc } \\
\text { lá }\end{array}$} & \multirow{3}{*}{ Có } & $\mathrm{n}$ & 29 & 132 & \\
\hline & & \% hút thuốc & $18 \%$ & $82 \%$ & $100 \%$ \\
\hline & & $\%$ theo $\mathrm{CNHH}$ & $33.3 \%$ & $66.3 \%$ & $56.3 \%$ \\
\hline & \multirow{3}{*}{ Không } & $\mathrm{n}$ & 58 & 67 & 125 \\
\hline & & \% hút thuốc & $46,4 \%$ & $53,6 \%$ & $100 \%$ \\
\hline & & $\%$ theo $\mathrm{CNHH}$ & $66.7 \%$ & $33.7 \%$ & $43.7 \%$ \\
\hline \multirow{2}{*}{\multicolumn{2}{|c|}{ Tổng }} & $\mathrm{n}$ & 87 & 199 & 286 \\
\hline & & Tỷ lệ \% & $100.0 \%$ & $100.0 \%$ & $100.0 \%$ \\
\hline \multirow{4}{*}{$\begin{array}{l}\text { Tiếp xúc } \\
\text { khói bụi }\end{array}$} & Có & $\mathrm{n}$ & 74 & 166 & 240 \\
\hline & & Tỷ lệ (\%) & $84,1 \%$ & $83,8 \%$ & $83.9 \%$ \\
\hline & Không & $\mathrm{n}$ & 14 & 32 & 46 \\
\hline & & Tỷ lệ (\%) & $15.9 \%$ & $16.2 \%$ & $16.1 \%$ \\
\hline \multirow{2}{*}{\multicolumn{2}{|c|}{ Tổng }} & $\mathrm{n}$ & 88 & 198 & 286 \\
\hline & & Tỷ lệ (\%) & $100.0 \%$ & $100.0 \%$ & $100.0 \%$ \\
\hline
\end{tabular}

Nhận xét: Theo kết quả nghiên cứu bảng trên chúng tôi nhận thấy;

Nhóm tiền sử hút thuốc lá có 161 bệnh nhân chiếm 56,3\%, trong đó chiếm đại đa số 132 bệnh nhân có rối loạn tắc nghẽn mức độ trung bình đến nặng chiếm tỷ lệ $82 \%$ và có 29 bệnh nhân có rối loạn tắc nghẽn mức độ nhe chiếm tỷ lệ 18\%, sự khác biệt có ý nghĩa thống kê với $p<0,01$.
Nhóm không có tiền sử hút thuốc lá: có 125 bệnh nhân chiếm tỷ lệ $43,7 \%$, trong đó có 67 bểnh nhân có rối loạn tắc nghẽn mức độ trung bình đến nặng chiếm tỷ lệ $53,6 \%$ và có 58 bệnh nhân có rối loạn tắc nghẽn mức độ nhẹ chiếm tỷ lệ 46,4\%, khổng có sự khác biệt về chức năng hô hấp ở nhóm không có tiền sử hút thuốc lá. 
Nhóm bệnh nhân có rối loạn tắc nghẽn mức độ trung bình - rất nặng, có tỷ lệ bênh nhân tiền sử hút thuốc lá $83,8 \%$ cao hơn nhiều so với tỷ lệ bệnh nhân không hút thuốc lá $16,2 \%$, sự khác biệt có ý nghĩa thống kê với $p<0,01$.

Trong 286 bênh nhân nghiên cứu có tới 240 bệnh nhân có tiền sử tiếp xúc khói bụi (bao gồm hút thuốc lá chủ động, hút thuốc thụ động, bụi nghề nghiệp) chiếm tỷ lệ $83,9 \%$, và có 46 bệnh nhân không có tiền sử tiếp xúc với khói bụi chiếm tỷ lệ $16,1 \%$. Tỷ lệ này phù hợp với tài liệu bệnh học nội khoa, có tới trên $80 \%$ các bệnh nhân COPD trong tiền sử có liên quan tới khói thuốc lá [1].
3.3. Đánh giá tuân thủ điêu trị Bảng 3: Mức độ tuân thủ điều trì

\begin{tabular}{|c|c|c|}
\hline Mức độ tuân thủ & $\mathbf{n}$ & Tỷ lệ (\%) \\
\hline Tuân thủ tốt & 141 & $49,3 \%$ \\
\hline Tuân thủ trung bình & 92 & $32,2 \%$ \\
\hline Tuân thủ kém & 53 & $18,5 \%$ \\
\hline Tổng & 286 & $100 \%$ \\
\hline
\end{tabular}

Nhận xét: Trong nhóm nghiên cứu có 141 bệnh nhân tuân thủ điều trị tốt chiếm tỷ lệ 49,3 \%, có 145 bệnh nhân tuân thủ điều trị ở mức trung bình và kém chiếm tỷ lệ $50,7 \%$ (tuân thủ trung bình $32,2 \%$, tuân thủ kém 18,5\%).

Bảng 4. Đặc điểm tuân thủ sử dụng thuốc điều trị. Đặc điểm theo thang điểm Morisky

\begin{tabular}{|c|c|c|c|}
\hline \multicolumn{2}{|l|}{ Đăcc điểm theo thang điểm Morisky } & $N ; 286$ & Tỷ lệ (\%) \\
\hline \multirow{2}{*}{ 1. Ông/bà có đôi lúc quên uống thuốc không? } & Có & 73 & 25,5 \\
\hline & Không & 213 & 74,5 \\
\hline \multirow{2}{*}{$\begin{array}{l}\text { 3. Trong } 2 \text { tuần qua có ngày nào Ông/bà } \\
4 . \quad \text { không dùng thuốc không }\end{array}$} & Có & 67 & 23,4 \\
\hline & Không & 219 & 76,6 \\
\hline \multirow{2}{*}{$\begin{array}{l}\text { 3. Ông/bà có từng bỏ hay ngưng dùng thuốc mà không báo } \\
\text { bác sỹ vì cảm thấy mệt khi dùng thuốc? }\end{array}$} & Có & 27 & 9,4 \\
\hline & Không & 259 & 90,6 \\
\hline \multirow{2}{*}{$\begin{array}{l}\text { 4. Khi Öng/bà đi du lịch, đi chơi có đôi lúc quên mang theo } \\
\text { thuốc không? }\end{array}$} & Có & 41 & 14,3 \\
\hline & Không & 245 & 85,7 \\
\hline \multirow{2}{*}{ 5. Ông/bà có uống đủ thuốc ngày hôm qua không? } & Có & 260 & 90,9 \\
\hline & Không & 26 & 9,1 \\
\hline \multirow{2}{*}{$\begin{array}{l}\text { 6. Khi Ông/bà cảm thấy kiểm soát được triệu chứng của } \\
\text { mình, có đôi lúc không uống thuốc không? }\end{array}$} & Có & 27 & 9,4 \\
\hline & Không & 259 & 90,6 \\
\hline \multirow{2}{*}{$\begin{array}{l}\text { 7. Ông/bà có thấy bất tiện khi phải tuân theo } \\
\text { kế hoạch điều trị không? }\end{array}$} & Có & 42 & 14,7 \\
\hline & Không & 244 & 85,3 \\
\hline \multirow{2}{*}{$\begin{array}{l}\text { 8. Ông/bà có thường xuyên thấy khó khăn khi phải nhớ dùng } \\
\text { tất cả thuốc không? }\end{array}$} & Có & 51 & 17,8 \\
\hline & Không & 235 & 82,2 \\
\hline
\end{tabular}

Nhận xét: - Theo bảng trên ta thấy có tới $25,5 \%$ bệnh nhân quên dùng thuốc, tỷ lệ trong 2 tuần có ngày không dùng thuốc $23,4 \%$.

- Tỷ lệ bỏ thuốc vì mệt khi dùng thuốc khá thấp chỉ chiếm 9,4\%

- Tỷ lệ nhớ mang theo thuốc bên người khi đi xa là khá cao $85,7 \%$ trong khi đó tỷ lệ quên không mang theo thuốc bên người chỉ chiếm $14,3 \%$.

- Tỷ lệ uống đủ thuốc ngày trước khi đi khám là rất cao $90,9 \%$

- Tỷ lệ bệnh nhân ngừng thuốc khi thấy bệnh được kiểm soát khá thấp chỉ chiếm 9,45.

- Có 14,7\% cảm thấy bất tiện khi dùng thuốc và $17,8 \%$ thấy khó khăn khi phải nhớ dùng tất cả các loại thuốc.

\section{BÀN LUẬN}

Đặc điểm chung của nhóm đối tượng nghiên cứu chủ yếu là người cao tuổi, tuổi trung bình nhóm đối tượng nghiên cứu 69,3 tuổi. Tỷ lệ này phù hợp vì bệnh phổi tắc nghẽn mạn tính xảy ra chủ yểu ở người cao tuổi thường trên 40 tuổi.
Nam giới có tỷ lệ $59,1 \%$ cao hơn so với nữ giới là $40,9 \%$. Điều này là phù hợp vì nam giới thường có thói quen hút thuốc lá và đó là yếu tố nguy cơ chính của bệnh phổi tắc nghẽn mạn tính.

Về yếu tố nguy cơ, thuốc lá là yếu tố nguy cơ chính của bệnh phổi tắc nghẽn mạn tính. Trong nghiên cứu chúng tôi thu được ở nhóm đối tượng có tiền sử hút thuốc lá có rối loạn thông khí tắc nghẽn mức độ trung bình đến nặng $82 \%$ cao hơn nhiều so với nhóm có rối loạn thông khí tắc nghẽn mức độ nhẹ $18 \%$, sự khác biệt có ý nghĩa thống kê với $p<0,01$. Như vậy hút thuốc lá là yếu tố nguy cơ chính và cũng là yếu tố làm tăng nặng tình trạng của bệnh. Trong nhóm không có tiền sử hút thuốc lá, tỷ lệ giữa nhóm có rối loạn tắc nghẽn mạn tính mức độ trung bình đến nặng 53,6\% không có sự khác biệt với nhóm có rối loan tắc nghẽn man tính mức đô nhe 46,4\%.

Bệnh phổi tắc nghẽn mạn tính là một bệnh mạn tính, bệnh nhân cần phải sử dụng thuốc lâu dài, đủ liều lượng, đủ số lượng theo chỉ định của bác sỹ. Trong nghiên cứu của chúng tôi, tỷ lệ 
bệnh nhân tuân thủ điều trị tốt 49,3\%, bệnh nhân tuân thủ trung bình là 32,2\%, bệnh nhân tuân thủ kém là $18,5 \%$. Tỷ lệ tuân thủ điều trị tốt của chúng tôi cao hơn so với kết quả của Nguyễn Hoài Thu khi nghiên cứu tỷ lệ tuân thủ điêu trị của bệnh nhân COPD tại Bệnh viện Bạch mai năm 2016, tuân thủ tốt $37,9 \%$, tuân thủ trung bình $41,2 \%$, tuân thủ kém $20,9 \%$ [4].

Bệnh nhân cần hiểu được bệnh của họ và tầm quan trọng của việc tuân thủ điều trị, qua đó giúp họ tuân thủ điều trị tốt hơn, nâng cao sức khỏe và chất lượng điều trị. Tìm hiểu kỹ hơn về các trường hợp không tuân thủ điều trị chúng tôi nhận thây: có $25,5 \%$ bệnh nhân quên sử dụng thuốc, có $23,5 \%$ trong 2 tuần có ngày khổng dùng thuốc, có $17,8 \%$ cảm thấy khó khăn khi phải nhớ dùng tất cả các loại thuốc, đây là 3 nguyên nhân phổ biến dẫn tới bệnh nhân tuân thủ điều trị kém. Điều này có thể các bệnh nhân cao tuổi thường mắc nhiều bệnh mạn tính cùng một lúc trong đó có bệnh sa sút trí tuệ, số lượng thuốc hàng ngày bệnh nhân phải uống trung bình lên đến 4- 5 loại thuốc. Những nguyên nhân này làm cho bệnh nhân cao tuổi khó khăn trong việc tuân thủ tốt phác đồ điều trị, vì vậy cần có sự hỗ trợ của người nhà, sự nhắc nhở thường xuyên của nhân viên y tế trực tiếp hay qua các phương tiện truyền thông như tin nhắn điện thoại định kỳ mới giúp cho bệnh nhân tuân thủ tốt phác đồ điều trị.

\section{KẾT LUẬN}

Tỷ lệ bệnh nhân chưa tuân thủ điều trị tốt trong nghiển cứu của chúng tôi còn khá cao $50,7 \%$, mà nguyên nhân chính là do bệnh nhân quên dùng thuốc hoặc quên nhớ tất cả các loại thuốc phải dùng. Để khắc phục tình trạng này cần có sự hỗ trợ nhắc nhở thường xuyên của người nhà, của nhân viên y tế để giúp bệnh nhân tuân thủ điều trị tốt hơn.

\section{TÀI LIẸU THAM KHẢO}

1. Bệnh học nội khoa tập 1- Đại họ $Y$ Hà nội, "Bệnh phổi tắc nghẽn mạn tính", Nhà xuất bản y học 2018, tr 42-58.

2. Phạm Thắng, Đồ Thị Khánh Hỷ (2009), 'Báo cáo tổng quan về chính sách chăm sóc người già thích ứng với thay đổi cỡ cấu tuổi tại Việt Nam".

3. Đinh Ngọc Sỹ, Nguyễn Văn Thành, Nguyễn Viết Nhung va CS (2016) "Tăng cường tuân thủ quản lý và điều trị Hen và COPD ở cộng đồng" Hội Lao và Bệnh phối Việt Nam (2016).

4. Nguyễn Hoài Thu (2016), Đánh giá tuân thủ điểu trị và kỹ thuật sữ dụng các thuốc dang hít trên bệnh nhân bệnh phổi tắc nghẽn mạn tính tại Bênh viện Bach Mai. Luâan văn Thạc sỹ Dược học.

5. Trần Thị Thừy Nhi (2021), Nghiển cưu tuẩn thủ sử dụng thuốc theo thang điêm Morisky (MMAS-8) và hiệu quả tư vấn trên bệnh nhân Đái tháo đường typ 2.

6. Lam WY, Fresco P: Medication adherence measures: an overview. BioMed research international 2015, 2015.

7. Nguyen T, Cao HT, Quach DN, Le KK, Au SX, Pham ST, Nguyen TH, Pham TT, Taxis K: The Vietnamese Version of the Brief Illness Perception Questionnaire and the Beliefs about Medicines Questionnaire: Translation and Cross-cultural Adaptation. Tropical Medicine \& International Health 2019, 24(12):1465-1474.

8. GOLD (2018), "Global Strategy for diagnosis management and prevention of COPD", http://w.w.w.goldcopd.org/Guidline, 2018 revison.'

9. Morisky DE, Ang A, Krousel-Wood M, Ward H (2008), "Predictive Validity of a Medication Adherence Measure for Hypertension Control", Journal of Hypertension, 10(5), pp. 348-354.

\section{CẮT XƠ RỐN GAN RộNG RÃI TRONG PHẪU THUẬT KASAI ĐIỀU TRI TEO ĐƯỜ'NG MÂ̂T BẨM SINH}

\section{Nguyễn Huy Toàn ${ }^{1}$, Phạm Duy Hiền ${ }^{2}$, Vũ Tiến Tùng ${ }^{3}$}

\section{TÓM TẮT.}

Mục tiêu: Đánh giá kết quả phẫu thuật Kasai có cắt xớ rốn gan rộng rãi trong điều trị teo đường mật bẩm sinh tại bệnh viện nhi Trung Ương giai đoận

\footnotetext{
${ }^{1}$ Bệnh viện đa khoa tỉnh Hòa Bình.

Bệnh viện Nhi trung ương.

3 Trường Đại hoc Y Dược Thái Binh

Chịu trách nhiệm chính: Nguyễn Huy Toàn

Email: huytoan080884@gmail.com

Ngày nhận bài: 11.8.2021

Ngày phản biện khoa học: 12.10.2021

Ngày duyệt bải: 20.10.2021
}

2016-2020. Đối tượng và phương pháp nghiên cứu: Nghiên cứu hồi cứu mô tả loạt ca bệnh bao gồm 172 bệnh nhân được chẩn đoán teo đường mật bẩm sinh, được điều trị bằng phẫu thuật Kasai có cắt xơ rốn gan rộng rãi tại bệnh viện Nhi trung ương từ $01 / 2016$ đển 12/2020. Các tiệu chuẩn nghiên cứu bao gồm các đánh giá chi tiết phẫu thuật, các biến chứng sau mổ, tỷ lệ tử vong và một số yếu tố liên quan. Kết quả: Thời gian mổ trung bình là $152.1 \pm 28.9$ phút. Thời gian nằm viện sau mổ trung bình $11,4 \pm 2,69$ ngày. Đánh giá tại thời điểm ra viện kết quả tốt chiếm $77,3 \%$, kết quả trung bình chiếm 22,1\%. Các biến chứng thường gặp là nhiếm trùng đường mật, suy gan sau mổ, rối loạn điện giải. Tại thời điểm kết thúc 